\title{
An Intelligent Water Drop Algorithm for Solving Optimal Reactive Power Dispatch Problem
}

\author{
K. Lenin and M. Surya Kalavathi \\ Department of electrical \& electronics engineering \\ Jawaharlal Nehru Technological University Hyderabad \\ Kukatpally, Hyderabad - 500 085, Andhra Pradesh, India \\ gklenin@gmail.com
}

\begin{abstract}
Abstarct: This paper presents an algorithm for solving the multi-objective reactive power dispatch problem in a power system. Modal analysis of the system is used for static voltage stability assessment. Loss minimization and maximization of voltage stability margin are taken as the objectives. Generator terminal voltages, reactive power generation of the capacitor banks and tap changing transformer setting are taken as the optimization variables. In this paper an intelligent water drop (IWD) algorithm has been proposed to solve this combinatorial optimization problem. Intelligent water drop algorithm is a swarm-based nature inspired optimization algorithm, which has been inspired from natural rivers. A natural river often finds good paths among lots of possible paths in its ways from source to destination and finally find almost optimal path to their destination. These ideas are embedded into proposed algorithm for solving reactive dispatch problem.
\end{abstract}

Index Terms: Modal analysis, optimal reactive power, Transmission loss, Optimization, Intelligent Water Drop Algorithm.

\section{Introduction}

Optimal reactive power dispatch problem is one of the difficult optimization problems in power systems. The sources of the reactive power are the generators, synchronous condensers, capacitors, static compensators and tap changing transformers. The problem that has to be solved in a reactive power optimization is to determine the required reactive generation at Various locations so as to optimize the objective function. Here the reactive power dispatch problem involves best utilization of the existing generator bus voltage magnitudes, transformer tap setting and the output of reactive power sources so as to minimize the loss and to enhance the voltage stability of the system. It involves a non linear optimization problem. Various mathematical techniques have been adopted to solve this optimal reactive power dispatch problem. These include the gradient method [1-2], Newton method [3] and linear programming [4-7].The gradient and Newton methods suffer from the difficulty in handling inequality constraints. To apply linear programming, the input- output function is to be expressed as a set of linear functions which may lead to loss of accuracy. Recently global Optimization techniques such as genetic algorithms have been proposed to solve the reactive power flow problem $[8,9]$.

In this paper, a new approach intelligent water drop (IWD) algorithm [10], is used to solve the voltage contsraint reactive power despatch problem, the proposed algorithm identify the optimal values of generation bus voltage magnitudes, transformer tap setting and the output of the reactive power sources as to minimize the transmission loss to improve the voltage stability. The effectiveness of the proposed approach is demonstrated through IEEE-30 bus

Received: July $8^{\text {th }}, 2012$. Accepted: October $30^{\text {th }}, 2012$ 
system. The test results show the proposed algorithm gives better results with less computational burden and is fairly consistent in reaching the near optimal solution

In recent years, the problem of voltage stability and voltage collapse has become a major concern in power system planning and operation. To enhance the voltage stability, voltage magnitudes alone will not be a reliable indicator of how far an operating point is from the collapse point [11]. The reactive power support and voltage problems are intrinsically related. Hence, this paper formulates the reactive power dispatch as a multi-objective optimization problem with loss minimization and maximization of static voltage stability margin (SVSM) as the objectives. Voltage stability evaluation using modal analysis [12] is used as the indicator of voltage stability.

\section{Voltage Stability Evaluation}

\section{A. Modal analysis for voltage stability evaluation}

Modal analysis is one of the methods for voltage stability enhancement in power systems. In this method, voltage stability analysis is done by computing eigen values and right and left eigen vectors of a jacobian matrix. It identifies the critical areas of voltage stability and provides information about the best actions to be taken for the improvement of system stability enhancements. The linearized steady state system power flow equations are given by.

$$
\left[\begin{array}{l}
\Delta P \\
\Delta Q
\end{array}\right]=\left[\begin{array}{l}
J_{p \theta} J_{P V} \\
J_{Q \theta} J_{Q V}
\end{array}\right]\left[\begin{array}{l}
\Delta \theta \\
\Delta V
\end{array}\right]
$$

where

$\Delta P=$ Incremental change in bus real power.

$\Delta Q=$ Incremental change in bus reactive Power injection

$\Delta \theta=$ incremental change in bus voltage angle.

$\Delta V=$ Incremental change in bus voltage Magnitude

$\mathrm{J}_{\mathrm{p} \theta}, \mathrm{J}_{\mathrm{PV}}, \mathrm{J}_{\mathrm{Q} \theta}, \mathrm{J}_{\mathrm{QV}}$ jacobian matrix are the sub-matrixes of the System voltage stability is affected by both P and Q. However at each operating point we keep P constant and evaluate voltage stability by considering incremental relationship between $\mathrm{Q}$ and $\mathrm{V}$.

To reduce (1), let $\Delta P=0$, then.

$$
\begin{aligned}
& \Delta \mathrm{Q}=\left[\mathrm{J}_{\mathrm{QV}}-\mathrm{J}_{\mathrm{Q} \theta} \mathrm{J}_{\mathrm{P} \theta}{ }^{-1} \mathrm{~J}_{\mathrm{PV}}\right] \Delta \mathrm{V}=\mathrm{J}_{\mathrm{R}} \Delta \mathrm{V} \\
& \Delta V=J^{-1} \Delta Q
\end{aligned}
$$

Where

$$
\mathrm{J}_{\mathrm{R}}=\left(\mathrm{J}_{\mathrm{QV}}-\mathrm{J}_{\mathrm{Q} \theta} \mathrm{J}_{\mathrm{P} \theta}{ }^{-1} \mathrm{~J} \mathrm{PV}\right)
$$

$J_{R}$ is called the reduced Jacobian matrix of the system.

B. Modes of Voltage instability:

Voltage Stability characteristics of the system can be identified by computing the eigen values and eigen vectors, Let

$$
\mathrm{J}_{\mathrm{R}}=\xi \wedge \eta
$$

Where,

$$
\xi=\text { right eigenvector matrix of } J_{R}
$$


$\eta=$ left eigenvector matrix of $J_{R}$

$=$ diagonal eigenvalue matrix of $J_{R}$ and

$$
\mathrm{J}_{\mathrm{R}}{ }^{-1}=\xi \wedge-1 \eta
$$

From (3) and (6), we have

$$
\Delta V=\xi^{-1} \eta \Delta Q
$$

Or

$$
\Delta V=\sum_{\mathrm{i}} \underset{\lambda_{\mathrm{i}}}{\xi_{\mathrm{i}} \eta \mathrm{i}} \Delta \mathrm{Q}
$$

where $\xi \mathrm{i}$ is the ith column right eigenvector and $\eta$ the $\mathrm{i}^{\text {th }}$ row left eigenvector of $J_{R}$. $\lambda_{\mathrm{i}}$

is the ith eigen value of JR.

The $\mathrm{i}^{\text {th }}$ modal reactive power variation is,

$$
\Delta \mathrm{Q}_{\mathrm{mi}}=\mathrm{K}_{\mathrm{i}} \xi_{\mathrm{i}}
$$

where,

$$
\mathrm{K}_{\mathrm{i}}=\sum_{\mathrm{j}} \xi_{\mathrm{ij}}^{2}-1
$$

Where,

$\xi \mathrm{ji}$ is the jth element of $\xi \mathrm{i}$

The corresponding $\mathrm{i}^{\text {th }}$ modal voltage variation is

$$
\Delta \mathrm{V}_{\mathrm{mi}}=[1 / \lambda \mathrm{i}] \Delta \mathrm{Q}_{\mathrm{mi}}
$$

It is seen that, when the reactive power variation is along the direction of $\xi_{\mathrm{i}}$ the corresponding voltage variation is also along the same direction and magnitude is amplified by a factor which is equal to the magnitude of the inverse of the $i^{\text {th }}$ eigenvalue. In this sense, the magnitude of each eigenvalue $\lambda_{i}$ determines the weakness of the corresponding modal voltage. The smaller the magnitude of $\lambda i$, the weaker will be the corresponding modal voltage. If $\left|\lambda_{\mathrm{i}} \quad\right|=0$ the $\mathrm{i}^{\text {th }}$ modal voltage will collapse because any change in that modal reactive power will cause infinite modal voltage variation.

In (8), let $\Delta \mathrm{Q}=\mathrm{e}_{\mathrm{k}}$ where $\mathrm{e}_{\mathrm{k}}$ has all its elements zero except the $\mathrm{k}^{\text {th }}$ one being 1 . Then,

$$
\begin{gathered}
\Delta V=\sum_{i} \frac{\eta_{1 k} \xi_{1}}{\lambda_{1}} \\
\text { where } \eta_{1 k} \text { the } \mathrm{k}^{\text {th }} \text { element of } \eta_{i} . \\
\mathrm{V}-\mathrm{Q} \text { sensitivity at bus k, } \\
\frac{\partial V_{k}}{\partial Q_{k}}=\sum_{i} \frac{\xi_{k i} \eta_{i k}}{\lambda_{1}}=\sum_{i} \frac{P_{k i}}{\lambda_{1}}
\end{gathered}
$$

A system is voltage stable if the eigenvalues of the Jacobian are all positive. Thus the results for voltage stability enhancement using modal analysis for the reduced jacobian matrix is when

eigen values $\lambda i>0$, the system is under stable condition eigen values $\lambda \mathrm{i}<0$, the system is unstable

eigen values $\lambda i=0$, the system is critical and collapse state occurs 


\section{Problem Formulation}

The optimal reactive power dispatch problem is formulated as an optimization problem in which a specific objective function is minimized while satisfying a number of equality and inequality constraints. The objectives of the reactive power dispatch problem considered here is to minimize the system real power loss and maximize the static voltage stability margins (SVSM). This objective is achieved by proper adjustment of reactive power variables like generator voltage magnitude ( $g i$ ) $V$, reactive power generation of capacitor bank (Qci), and transformer tap setting (tk).Power flow equations are the equality constraints of the problems, while the inequality constraints include the limits on real and reactive power generation, bus voltage magnitudes, transformer tap positions and line flows. This objective function is subjected to the following constraints:

A. Real power losses:

To minimize the real power loss in the system, this can be expressed as

$$
\text { Minimini:e } P_{\text {Loss }}=\sum_{\substack{k \in \mathbb{N} \\ k=(i, j)}} g_{k}\left(V_{i}^{2}+V_{j}^{2}-2 V_{i} V_{j} \operatorname{Cos} \theta_{i j}\right)
$$

\section{B. Maximize SVSM:}

This is the most widely accepted index for proximity of voltage collapse. It is defined as the largest load change that the power system may sustain at a bus or collective of buses from a well defined operating point.(Base case) Using the modal analysis the minimal eigen value of the non-singular power flow jacobian matrix has been used to find the maximum static voltage stability margin in this proposed approach.

\section{Equality Constraints}

These constraints represent the typical load flow equation such as

$$
\begin{aligned}
& P_{i}-V_{i} \sum_{j=1}^{N_{B}} V_{j}\left(G_{i j} \operatorname{Cos} \theta_{i j}+B_{i j} \operatorname{Sin} \theta_{i j}\right)=0, i \in N_{B}-1 \\
& Q_{i}-V_{i} \sum_{j=1}^{N_{B}} V_{j}\left(G_{i j} \operatorname{Sin} \theta_{i j}-B_{i j} \operatorname{Cos} \theta_{i j}\right)=0, i \in N_{P Q}
\end{aligned}
$$

\section{Inequality Constraints}

These constraints represent the system operating constraints. Generator bus voltages (Vgi), reactive power generated by the capacitor (Qci), transformer tap setting (tk), are control variables and they are self restricted. Load bus voltages (Vload) reactive power generation of generator (Qgi) and line flow limit $(\mathrm{Sl})$ are state variables, whose limits are satisfied by adding a penalty terms in the objective function. These constraints are formulated as

(i) Voltage limits

$$
V_{i}^{\min } \leq V_{i} \leq V_{i}^{\max } ; i \in N_{B}
$$

(ii) Generator reactive power capability limit

$$
Q_{g i}^{\min } \leq Q_{g i} \leq Q_{g i}^{\max } ; i \in N_{g}
$$


(iii) Capacitor reactive power generation limit

$$
Q_{c i}^{\min } \leq Q_{c i} \leq Q_{c i}^{\max } ; i \in N_{c}
$$

(iv) Transformer tap setting limit

$$
t_{k}^{\min } \leq t_{k} \leq t_{k}^{\max } ; k \in N_{T}
$$

(v) Transmission line flow limit

$$
S_{l} \leq S_{l}^{\max } ; l \in N_{l}
$$

The equality constraints are satisfied by running the power flow program. The active power generation (Pgi), generator terminal bus voltages (Vgi) and transformer tap settings (tk) are the control variables and they are self restricted by the optimization algorithm. The active power generation at slack bus (Psl), load bus voltage (Vload) and reactive power generation (Qgi) are the state variables and are restricted by adding a quadratic penalty term to the objective function.

\section{Intelligent Water Drops Algorithm}

\section{A. Overview of Intelligent Water Drops Algorithm}

Intelligent Water Drops algorithm (IWD) [18] is a swarm based nature-inspired optimization algorithm, which has been inspired from natural rivers and how they find almost optimal path to their destination. A natural river often finds good paths among lots of possible paths in its ways from the source to destination. These near optimal or optimal paths follow from actions and reactions occurring among the water drops and the water drops with their riverbeds. In the IWD algorithm, several artificial water drops cooperate to change their environment in such a way that the optimal path is revealed as the one with the lowest soil on its links. The solutions are incrementally constructed by the IWD algorithm. Consequently, the IWD algorithm is generally a constructive population-based optimization algorithm. The Intelligent Water Drop, IWD for short, flows in its environment has two important properties:

1. The amount of the soil it carries now, Soil (IWD).

2. The velocity that it is moving now, Velocity (IWD).

This environment depends on the problem at hand. In an environment, there are usually lots of paths from a given source to a desired destination, which the position of the destination may be known or unknown. If we know the position of the destination, the goal is to find the best (often the shortest) path from the source to the destination. In some cases, in which the destination is unknown, the goal is to find the optimum destination in terms of cost or any suitable measure for the problem. We consider an IWD moving in discrete finite-length steps. From its current location to its next location, the IWD velocity is increased by the amount nonlinearly proportional to the inverse of the soil between the two locations. Moreover, the IWDs soil is increased by removing some soil of the path joining the two locations. The amount of soil added to the IWD is inversely (and nonlinearly) proportional to the time needed for the IWD to pass from its current location to the next location. This duration of time is calculated by the simple laws of physics for linear motion. Thus, the time taken is proportional to the velocity of the IWD and inversely proportional to the distance between the two locations. Another mechanism that exists in the behavior of an IWD is that it prefers the paths with low soils on its beds to the paths with higher soils on its beds. To implement this behavior of path choosing, we use a uniform random distribution among the soils of the available paths such that the probability of the next path to choose is inversely proportional to the soils of the 
available paths. The lower the soil of the path, the more chance it has for being selected by the IWD.

\section{B. Intelligent Water Drops Algorithm}

The IWD algorithm gets a representation of the problem in the form of a graph (N, E) with the node set $\mathrm{N}$ and edge set $\mathrm{E}$. Then, each IWD begins constructing its solution gradually by traveling on the nodes of the graph along the edges of the graph until the IWD finally completes its solution. One iteration of the algorithm is complete when all IWDs have completed their solutions. After each iteration, the iteration best solution $\mathrm{T}^{\mathrm{IB}}$ is found and it is used to update the total best solution $\mathrm{T}^{\mathrm{TB}}$. The amount of soil on the edges of the iteration-best solution T IB is reduced based on the goodness (quality) of the solution. Then, the algorithm begins another iteration with new IWDs but with the same soils on the paths of the graph and the whole process is repeated. The algorithm stops when it reaches the maximum number of iterations iter $_{\max }$ or the total-best solution $\mathrm{T}^{\mathrm{TB}}$ reaches the expected quality. The IWD algorithm has two kinds of parameters. One kind is those that remain constant during the lifetime of the algorithm and they are called 'static parameters'. The other kind is those parameters of the algorithm, which are dynamic and they are reinitialized after each iteration of the algorithm.

The algorithm of IWD is specified in the following steps:

1. The graph $(\mathrm{N}, \mathrm{E})$ of the problem is given to the algorithm. The quality of the total-best solution $\mathrm{T}^{\mathrm{TB}}$ is initially set to the worst value: $\mathrm{q}(\mathrm{TTB})=\infty$. The maximum number of iterations iter $_{\max }$ is specified by the user. The iteration count iter ${ }_{\text {count }}$ is set to zero. The number of water drops NIWD is set to a positive integer value, which is usually set to the number of nodes Nc of the graph. For velocity updating, the parameters are $\mathrm{av}=1, \mathrm{bv}=0.01$ and $\mathrm{cv}=1$. For soil updating, as $=1$, bs $=0.01$ and $\mathrm{cs}=1$. The local soil updating parameter $\rho n=0.9$, which is a small positive number less than one. The global soil updating parameter $\rho \mathrm{IWD}=0.9$, which is chosen from $[0,1]$. Moreover, the initial soil on each path (edge) is denoted by the constant InitSoil such that the soil of the path between every two nodes $i$ and $j$ is set by soill $(\mathrm{i}, \mathrm{j})=$ InitSoil. The initial velocity of each IWD is set to InitV $\mathrm{el}_{\text {l. }}$ Both parameters InitSoil and InitV el are user selected and they should be tuned experimentally for the application.

2. Every IWD has a visited node list Vc(IWD), which is initially empty: $V c(I W D)=$. Each IWDs velocity is set to $\mathrm{I}_{\mathrm{nit}} \mathrm{V}_{\mathrm{el}}$. All IWDs are set to have zero amount of soil.

3. Spread the IWDs randomly on the nodes of the graph as their first visited nodes.

4. Update the visited node list of each IWD to include the nodes just visited.

5. Repeat Steps 5.1 to 5.4 for those IWDs with partial solutions.

$A$. For the IWD residing in node $i$, choose the next node $j$, which does not violate any constraints of the problem and is not in the visited node list Vc (IWD) of the IWD, using the following probability

$$
\begin{aligned}
& \mathrm{p}_{\mathrm{i}}{ }^{\text {IWD }}(\mathrm{j}): \\
& p_{i}^{I W D}(j)=\frac{f(\operatorname{soil}(i, j))}{\sum_{k \notin V_{c}(I W D)} f(\operatorname{soil}(i, k))}
\end{aligned}
$$

such that

$$
f(\operatorname{soil}(i, j))=\frac{1}{\epsilon_{s}+g(\operatorname{soil}(i, j))}
$$


and

$$
g(\operatorname{soil}(i, j))=\left\{\begin{array}{l}
\operatorname{soil}(i, j) \quad \text { if } \min _{l \notin V_{c}(I W D)}(\operatorname{soil}(i, l)) \geq 0 \\
\operatorname{soil}(i, j)-\min _{l \notin V_{c}(I W D)}(\operatorname{soil}(i, l)) \quad \text { else }
\end{array}\right.
$$

Then, add the newly visited node $j$ to the list $\mathrm{Vc}$ (IWD).

B. For each IWD moving from node i to node j, update its velocity $v^{\text {ellWD }}(t)$ by

$$
v e e^{I W D}(t+1)=v e e^{I W D}(t)+\frac{a_{v}}{b_{1}+c_{1} \cdot \operatorname{sol}^{i} l^{2}(i, j)}
$$

where vel ${ }^{\mathrm{IWD}}(\mathrm{t}+1)$ is the updated velocity of the IWD.

C. For the IWD moving on the path from node $i$ to node $j$, compute the soil $\Delta$ soil $(i, j)$ that the IWD

loads from the path by

$$
\Delta \operatorname{soil}(i, j)=\frac{a_{s}}{b_{s}+c_{s} \cdot \operatorname{time}^{2}\left(i, j ; v e l l^{I W D}(t+1)\right)}
$$

such that

$$
\text { time }\left(i, j ; v e^{I W D}(t+1)\right)=\frac{H U D(j)}{v e l^{I W D}(t+1)}
$$

where the heuristic undesirability $\mathrm{HUD}(\mathrm{j})$ is defined appropriately for the given problem.

D. Update the soil soil $(i, j)$ of the path from node $i$ to node $j$ traversed by that IWD and also update the soil that the IWD carries soil ${ }^{I W D}$ by

$$
\begin{aligned}
& \operatorname{soil}(i, j)=\left(1-\rho_{n}\right) \cdot \operatorname{soil}(i, j)-\rho_{n} \cdot \Delta \operatorname{soil}(i, j) \\
& \operatorname{soil}^{I W D}=\operatorname{soil}^{I W D}+\Delta \operatorname{soil}(i, j)
\end{aligned}
$$

6. Find the iteration-best solution T IB from all the solutions $\mathrm{T}^{\mathrm{IWD}}$ found by the IWDs using

$$
T^{I B}=\arg \max _{\forall T^{I W D}} q\left(T^{I W D}\right)
$$

where function $\mathrm{q}($.) gives the quality of the solution.

7. Update the soils on the paths that form the current iteration-best solution $\mathrm{T}^{\mathrm{IB}}$ by

$$
\operatorname{soil}(i, j)=(1+\rho I W D) \cdot \operatorname{soil}(i, j)-\rho_{I W D} \cdot \frac{1}{\left(N_{I B}-1\right)} \cdot \operatorname{soil}_{I B}^{I W D} \forall(i, j) \in T^{I B}
$$

where $\mathrm{N}_{\mathrm{IB}}$ is the number of nodes in the solution $\mathrm{T}^{\mathrm{IB}}$

8. Update the total best solution $\mathrm{T}^{\mathrm{TB}}$ by the current iteration-best solution $\mathrm{T}_{\text {IB }}$ using 
K. Lenin, et al.

$$
T^{T B}= \begin{cases}T^{T B} & q\left(T^{T B}\right) \geq q\left(T^{I B},\right. \\ T^{I B} & \text { otherwise }\end{cases}
$$

9. Increment the iteration number by Iter ${ }_{\text {count }}=\operatorname{Iter}_{\text {count }}+1$. Then, go to Step 2 if Iter $_{\text {count }}<$ Iter $_{\max }$.

10. The algorithm stops here with the total-best solution $\mathrm{T}^{\mathrm{TB}}$.

And the flow chart of the proposed IWD algorithm which has been applied for reactive dispatch problem given the figure 1 .

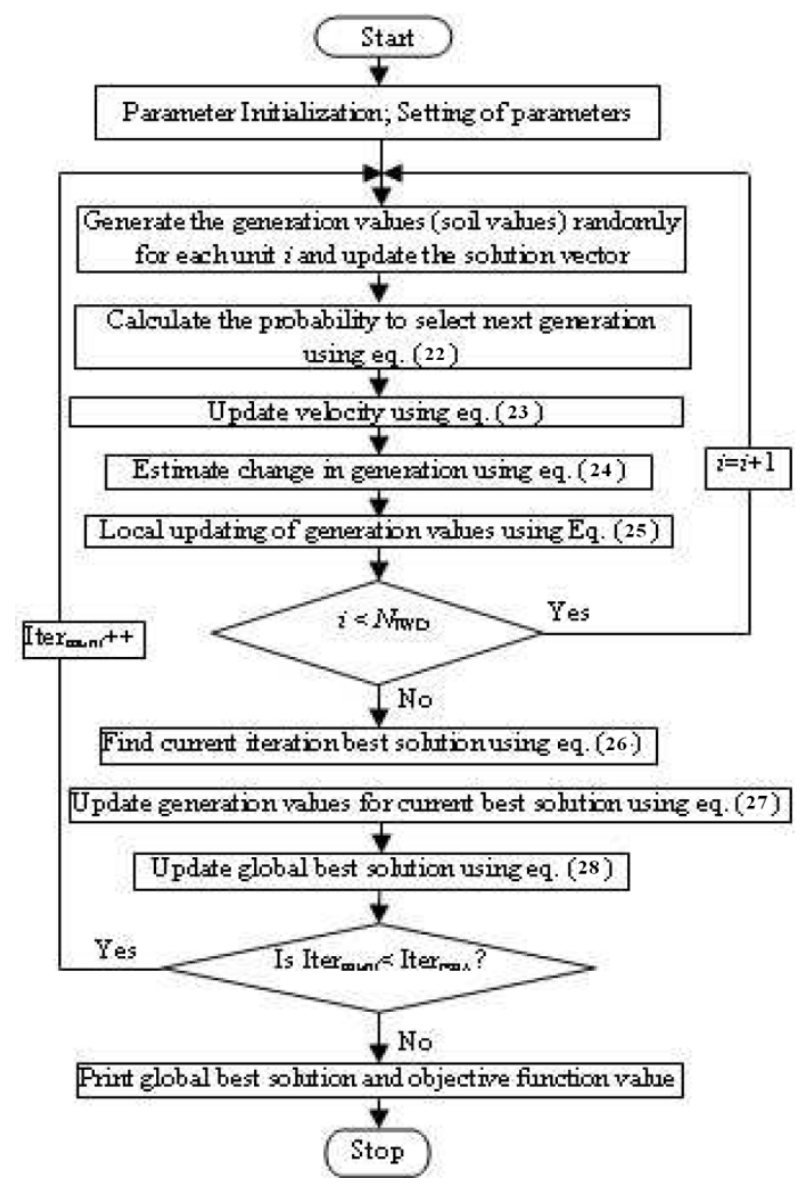

Figure 1. Flowchart of the proposed IWD algorithm

\section{Formation of the fitness function}

In the optimal reactive power dispatch problem, the objective is to minimize the total real power loss while satisfying the constraints (14) to (21). For each individual, the equality constraints are satisfied by running Newton-Raphson algorithm and the constraints on the state variables are taken into consideration by adding penalty function to the objective function. With the inclusion of the penalty factors, the new objective function then becomes,

$$
M i F=P_{\text {loss }}+w E i g
$$


Where

$$
\begin{gathered}
V P_{i}= \begin{cases}K_{v}\left(V_{i}-V_{i}^{\max }\right)^{2} & \text { if } V_{i}>V_{i}^{\max } \\
K_{v}\left(V_{i}-V_{i}^{\min }\right)^{2} & \text { if } V_{i}<V_{i}^{\min } \\
0 & \text { otherwise }\end{cases} \\
Q P_{g i}= \begin{cases}K_{q}\left(Q_{i}-Q_{i}^{\max }\right)^{2} & \text { if } Q_{i}>Q_{i}^{\max } \\
K q\left(Q_{i}-Q_{i}^{\min }\right)^{2} & \text { if } Q_{i}<Q_{i}^{\min } \\
0 & \text { otherwise }\end{cases} \\
L P_{l}= \begin{cases}K_{l}\left(S_{l}-S_{l}^{\max }\right)^{2} & \text { if } S_{l}>S_{l}^{\max } \\
0 & \text { otherwise }\end{cases}
\end{gathered}
$$

In the above expressions $w, K_{v}, K_{q}, K_{l}$ are the penalty factors for the eigen value, load bus voltage limit violation, generator reactive power limit violation and line flow limit violation respectively.

\section{Simulation Results}

In order to demonstrate the effectiveness and robustness of the proposed technique, minimization of real power loss under two conditions, without and with static voltage stability margin (SVSM) were considered. The validity of the proposed Algorithm technique is demonstrated on IEEE-30 bus system. The IEEE-30 bus system has 6 generator buses, 24 load buses and 41 transmission lines of which four branches are (6-9), (6-10), (4-12) and (28-27) are with the tap setting transformers. The real power settings are taken from [1]. The lower voltage magnitude limits at all buses are 0.95 p.u. and the upper limits are 1.1 for all the PV buses and 1.05 p.u. for all the PQ buses and the reference bus. The IWD algorithm based optimal reactive power dispatch algorithm was implemented using the MATLAB programmed and was executed on a Pentium computer. The results of the simulations are presented in below Tables I, II, III \&IV.. And in the table V shows clearly that proposed algorithm efficiently reduces the real power losses when compared to other given algorithms.

The parameters of algorithm used for simulation are: Number of water drops NIWD $=30$; Velocity updating parameters are $\mathrm{av}=1$, bv $=0.01$ and $\mathrm{cv}=1$; Soil updating parameters as as $=1$, bs $=0.01$ and $\mathrm{cs}=1$. Local soil updating parameter, $\rho \mathrm{n}=0.9$; Global soil updating parameter, $\rho \mathrm{IWD}=0.9$; InitSoil $=10000$; InitV el = 200; Itermax $=100$.

The optimal values of the control variables along with the minimum loss obtained are given in Table 1. Corresponding to this control variable setting, it was found that there are no limit violations in any of the state variables.

RPD including voltage stability constraint problem was handled in this case as a multiobjective optimization problem where both power loss and maximum voltage stability margin of the system were optimized simultaneously. Table II indicates the optimal values of these control variables. Also it is found that there are no limit violations of the state variables. It indicates the VSM has increased to 0.2362 from 0.2382 , an improvement in the system voltage stability. To determine the voltage security of the system, contingency analysis was conducted using the control variable setting obtained in case 1 and case 2 . The eigen values corresponding to the four critical contingencies are given in Table III. From this result it is observed that the eigen values has increased appreciably for all contingencies in the second case. 
K. Lenin, et al.

Table 1. Results of IWD - RPD optimal control variables

\begin{tabular}{|c|c|}
\hline Control variables & Variable setting \\
\hline V1 & 1.048 \\
V2 & 1.046 \\
V5 & 1.044 \\
V8 & 1.035 \\
V11 & 1.012 \\
V13 & 1.042 \\
T11 & 1.09 \\
T12 & 1.02 \\
T15 & 1.1 \\
T36 & 1.0 \\
Qc10 & 3 \\
Qc12 & 3.4825 \\
Qc15 & 3 \\
Qc17 & 3 \\
Qc20 & 3 \\
power loss & 3 \\
Qc2 & 3 \\
\hline
\end{tabular}


Table 2. Results Of IWD -Voltage Stability Control Reactive Power Dispatch Optimal Control Variables:

\begin{tabular}{|c|c|}
\hline Control Variables & Variable Setting \\
\hline V1 & 1.046 \\
\hline V2 & 1.042 \\
\hline V5 & 1.039 \\
\hline V8 & 1.032 \\
\hline V11 & 1.008 \\
\hline V13 & 1.038 \\
\hline $\mathrm{T} 11$ & 0.091 \\
\hline $\mathrm{T} 12$ & 0.090 \\
\hline $\mathrm{T} 15$ & 0.092 \\
\hline $\mathrm{T} 36$ & 0.090 \\
\hline Qc10 & 2 \\
\hline Qc12 & 1 \\
\hline Qc15 & 3 \\
\hline Qc17 & 2 \\
\hline Qc20 & 0 \\
\hline Qc23 & 3 \\
\hline Qc24 & 4 \\
\hline Qc29 & 4 \\
\hline Real power loss & 5.0099 \\
\hline SVSM & 0.2382 \\
\hline
\end{tabular}

Table 3. Voltage Stability Under Contingency State

\begin{tabular}{|l|l|l|l|}
\hline SI.No & \multicolumn{1}{|c|}{ Contigency } & $\begin{array}{c}\text { ORPD } \\
\text { Setting }\end{array}$ & \multicolumn{1}{|c|}{$\begin{array}{c}\text { Vscrpd } \\
\text { Setting }\end{array}$} \\
\hline 1 & $28-27$ & 0.1400 & 0.1422 \\
\hline 2 & $4-12$ & 0.1658 & 0.1662 \\
\hline 3 & $1-3$ & 0.1784 & 0.1754 \\
\hline 4 & $2-4$ & 0.2012 & 0.2032 \\
\hline
\end{tabular}


K. Lenin, et al.

Table 4. Limit Violation Checking of State Variables

\begin{tabular}{|c|c|c|c|c|}
\hline \multirow{2}{*}{$\begin{array}{c}\text { State } \\
\text { variables }\end{array}$} & \multicolumn{2}{|c|}{ limits } & \multirow{2}{*}{ ORPD } & \multirow{2}{*}{ VSCRPD } \\
\hline & Lower & upper & & \\
\hline Q1 & -20 & 152 & 1.3422 & -1.3269 \\
\hline Q2 & -20 & 61 & 8.9900 & 9.8232 \\
\hline Q5 & -15 & 49.92 & 25.920 & 26.001 \\
\hline Q8 & -10 & 63.52 & 38.8200 & 40.802 \\
\hline Q11 & -15 & 42 & 2.9300 & 5.002 \\
\hline Q13 & -15 & 48 & 8.1025 & 6.033 \\
\hline V3 & 0.95 & 1.05 & 1.0372 & 1.0392 \\
\hline V4 & 0.95 & 1.05 & 1.0307 & 1.0328 \\
\hline V6 & 0.95 & 1.05 & 1.0282 & 1.0298 \\
\hline V7 & 0.95 & 1.05 & 1.0101 & 1.0152 \\
\hline V9 & 0.95 & 1.05 & 1.0462 & 1.0412 \\
\hline V10 & 0.95 & 1.05 & 1.0482 & 1.0498 \\
\hline V12 & 0.95 & 1.05 & 1.0400 & 1.0466 \\
\hline V14 & 0.95 & 1.05 & 1.0474 & 1.0443 \\
\hline V15 & 0.95 & 1.05 & 1.0457 & 1.0413 \\
\hline V16 & 0.95 & 1.05 & 1.0426 & 1.0405 \\
\hline V17 & 0.95 & 1.05 & 1.0382 & 1.0396 \\
\hline V18 & 0.95 & 1.05 & 1.0392 & 1.0400 \\
\hline V19 & 0.95 & 1.05 & 1.0381 & 1.0394 \\
\hline V20 & 0.95 & 1.05 & 1.0112 & 1.0194 \\
\hline V21 & 0.95 & 1.05 & 1.0435 & 1.0243 \\
\hline V22 & 0.95 & 1.05 & 1.0448 & 1.0396 \\
\hline V23 & 0.95 & 1.05 & 1.0472 & 1.0372 \\
\hline V24 & 0.95 & 1.05 & 1.0484 & 1.0372 \\
\hline V25 & 0.95 & 1.05 & 1.0142 & 1.0192 \\
\hline V26 & 0.95 & 1.05 & 1.0494 & 1.0422 \\
\hline V27 & 0.95 & 1.05 & 1.0472 & 1.0452 \\
\hline V28 & 0.95 & 1.05 & 1.0243 & 1.0283 \\
\hline V29 & 0.95 & 1.05 & 1.0439 & 1.0419 \\
\hline V30 & 0.95 & 1.05 & 1.0418 & 1.0397 \\
\hline & & & & \\
\hline
\end{tabular}

Table 5. Comparison of Real Power Loss

\begin{tabular}{|c|c|}
\hline Method & Minimum loss \\
\hline Evolutionary programming[13] & 5.0159 \\
\hline $\begin{array}{c}\text { Genetic algorithm[14] } \\
\text { SVSM[15] }\end{array}$ & 4.665 \\
\hline $\begin{array}{c}\text { Real coded GA with Lindex as } \\
\text { Real coded genetic algorithm[16] }\end{array}$ & 4.5015 \\
\hline $\begin{array}{c}\text { Proposed IWD method } \\
\text { SV68 }\end{array}$ & 4.4825 \\
\hline
\end{tabular}




\section{Conclusion}

In this paper a novel approach based on Intelligent Water Drops (IWD) algorithm to solve optimal reactive power dispatch problem, considering various generator constraints, has been successfully applied.

The proposed method formulates reactive power dispatch problem as a mixed integer nonlinear optimization problem and determines control strategy with continuous and discrete control variables such as generator bus voltage, reactive power generation of capacitor banks and on load tap changing transformer tap position. To handle the mixed variables a flexible representation scheme was proposed.

The performance of the proposed algorithm demonstrated through its voltage stability assessment by modal analysis is effective at various instants following system contingencies. Also this method has a good performance for voltage stability Enhancement of large, complex power system networks. The effectiveness of the proposed method is demonstrated on IEEE 30-bus system

\section{Nomenclature:}

$\mathrm{N}_{\mathrm{B}}$ number of buses in the system

$\mathrm{N}_{\mathrm{g}}$ number of generating units in the system

$t_{k}$ tap setting of transformer branch $k$

$\mathrm{P}_{\mathrm{sl}}$ real power generation at slack bus

$\mathrm{V}_{\mathrm{i}}$ voltage magnitude at bus $\mathrm{i}$

$\mathrm{P}_{\mathrm{i}}, \mathrm{Q}_{\mathrm{i}}$ real and reactive powers injected at bus $\mathrm{i}$

$P_{g i}, Q_{g i}$ real and reactive power generations at bus $\mathrm{i}$

$\mathrm{G}_{\mathrm{ij}}, \mathrm{B}_{\mathrm{ij}}$ mutual conductance and susceptance between bus $\mathrm{i}$ and $\mathrm{j}$

$\mathrm{G}_{\mathrm{ii}}, \mathrm{B}_{\mathrm{ii}}$ self conductance and susceptance of bus $\mathrm{i}$

$\theta_{\mathrm{ij}}$ voltage angle difference between bus $\mathrm{i}$ and $\mathrm{j}$

\section{References}

[1] O.Alsac,and B. Scott, "Optimal load flow with steady state security",IEEE Transaction. PAS -1973, pp. 745-751.

[2] Lee K Y ,Paru Y M , Oritz J L - "A united approach to optimal real and reactive power dispatch", IEEE Transactions on power Apparatus and systems 1985: PAS-104: pp1147-1153

[3] A.Monticelli , M .V.F Pereira ,and S. Granville , "Security constrained optimal power flow with post contingency corrective rescheduling", IEEE Transactions on Power Systems :PWRS-2, No. 1, pp.175-182.,1987.

[4] Deeb N ,Shahidehpur S.M, "Linear reactive power optimization in a large power network using the decomposition approach". IEEE Transactions on power system 1990: 5(2) :pp $428-435$

[5] E. Hobson ,"Network consrained reactive power control using linear programming“ , IEEE Transactions on power systems PAS -99 (4) ,pp 868=877, 1980

[6] K.Y Lee,Y.M Park, and J.L Oritz, "Fuel -cost optimization for both real and reactive power dispatches", IEE Proceedings ; 131C,(3), pp.85-93.

[7] M.K. Mangoli, and K.Y. Lee, "Optimal real and reactive power control using linear programming”, Electric .Power System .Res, Vol.26, pp.1-10,1993.

[8] S.R.Paranjothi, and K.Anburaja, "Optimal power flow using refined genetic algorithm", Electric .Power Component. System, Vol. 30, 1055-1063, 2002.

[9] D. Devaraj, and B. Yeganarayana, "Genetic algorithm based optimal power flow for security enhancement”, IEE proc-Generation, .Transmission and. Distribution; 152, 6 November 2005.

[10] Hamed Shah-Hosseini, "The intelligent water drops algorithm: a natureinspired swarmbased optimization algorithm", International Journal of Bio-Inspired Computation, Vol. 1, Nos. 1 and 2, pp. 71-79, 2009. 
[11] C.A. Canizares , A.C.Z.de Souza and V.H. Quintana , " Comparison of performance indices for detection of proximity to voltage collapse ," IEEE Transactions on power system vol. 11. no.3 , pp.1441-1450, Aug 1996

[12] B.Gao, G.K Morison P. Kundur "voltage stability evaluation using modal analysis" IEEE Transactions on Power Systems, Vol 7, No .4 , November 1992.

[13] Wu Q H, Ma J T. Power system optimal reactive power dispatch using evolutionary programming. IEEE Transactions on power systems 1995; 10(3): 1243-1248

[14] S.Durairaj, D.Devaraj, P.S.Kannan ," Genetic algorithm applications to optimal reactive power dispatch with voltage stability enhancement", IE(I) Journal-EL Vol 87,September 2006.

[15] D.Devaraj ,'Improved genetic algorithm for multi - objective reactive power dispatch problem" European Transactions on electrical power 2007 ; 17: 569-581

[16] P. Aruna Jeyanthy and Dr. D. Devaraj "Optimal Reactive Power Dispatch for Voltage Stability Enhancement Using Real Coded Genetic Algorithm" International Journal of Computer and Electrical Engineering, Vol. 2, No. 4, August, 2010 1793-8163.

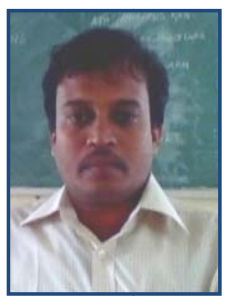

K. Lenin has received his B.E., Degree, electrical and electronics engineering in 1999 from university of madras, Chennai, India and M.E., Degree in power systems in 2000 from Annamalai University, Tamil Nadu, India. At present pursuing Ph.D., degree at JNTU, Hyderabad, India.

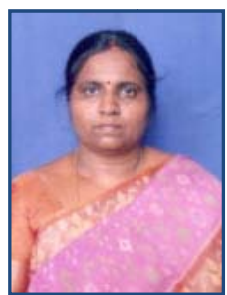

M. Surya Kalavathi has received her B.Tech. Electrical and Electronics Engineering from SVU, Andhra Pradesh, India and M.Tech, power system operation and control from SVU, Andhra Pradesh, India. she received her Phd. Degree from JNTU, hyderabad and Post doc. From CMU - USA. Currently she is Professor and Head of the electrical and electronics engineering department in JNTU, Hyderabad, India and she has Published 16 Research Papers and presently guiding 5 Ph.D. Scholars. She has specialised in Power Systems, High Voltage Engineering and Control Systems. Her research interests include Simulation studies on Transients of different power system equipment. She has 18 years of experience. She has invited for various lectures in institutes. 